\title{
FEM CALCULATIONS IN ANALYSIS OF STEEL SUBSEA WATER INJECTION FLOWLINES DESIGNING PROCESS
}

\author{
Michał Wodtke \\ Artur Olszewski ${ }^{1}$ \\ Artur Wójcikowski \\ ${ }^{1}$ Gdansk University of Technology, Poland \\ ${ }^{2}$ LOTOS Petrobaltic S.A., Poland
}

\begin{abstract}
The article describes the result of theoretical research aimed at assessing the loads and operating conditions of a Coiled Tubing pipeline injecting water, suspended to the mining platform of Lotos Petrobaltic. For this purpose, appropriate calculation models have been developed using the Finite Element Method (FEM), taking into account the nature of the analyzed object and its loads. The analyzes were carried out for two pipes (previously operated and newly proposed) differing in geometrical and strength parameters. The research was carried out for selected directions of load on the pipeline (originating from sea waves) and various variants of attaching the suspended pipeline to the mining platform.
\end{abstract}

Keywords: offshore engineering, water injection flowlines analysis, FEM simulations

\section{ORIGIN AND PURPOUS OF WORK}

Due to the planned increase in the injection pressure during the extraction of B8 deposit resources on the Baltic Sea operated by Lotos Petrobaltic, there was a need to select new pipes for water injection meeting the requirements of the implemented project. The injected water pipes are used to connect high pressure heads placed on the seabed (located in the place of the drilled wells) with the injection system located on the mining platform (Fig. 1). The solutions made in CT roll-up pipelines technology, the so-called "coil tubing" are used for this type of elements. The pipe used so far with a diameter of 4.5" (bed B3, Baltic Beta platform) was characterized by a maximum working pressure of 25 $\mathrm{MPa}$, while the expected operating pressure of water after modernization is to be about $30 \mathrm{MPa}$. For this reason, after analyzing the available solutions, a new pipe with a diameter of 4 " (with a maximum working pressure of $33 \mathrm{MPa}$ ) was initially selected.
The aim of the work was to perform a comparative analysis of CT pipes (currently used 4.5" and new 4") during their operation under extreme conditions of stress related to sea waves. The obtained results will allow to assess the safety of the newly proposed 4" pipe and using it under conditions of increased injection water pressure. In addition, as a result of the conducted analyzes, the values of loads transmitted by the injection pipelines to the platform structure as a result of the marine environment and operational factors will be determined. Knowledge of these stresses allowed for a further process of designing pipe holders as part of the modernization works of the Petrobaltic mining platform. 


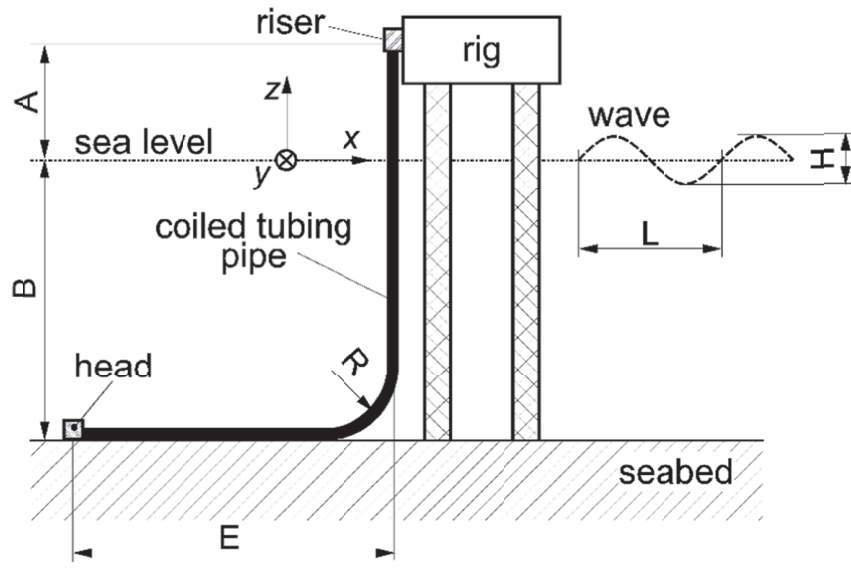

Fig. 1. Diagram of the location of the injection pipe holder with the indication of dimensional relations

\section{ASSUMPTIONS FOR ANALYSIS}

The exact determination of the actual working time (in years) for an object immersed in water (CT pipe) subjected to continuous variable loads caused by sea waves and variable internal pressure related to the water injection process is practically impossible. Of course, there are various methods available in the literature for determining fatigue strength (e.g. described in [1], [2], [3]), but they are characterized by a significant spread of results and a certain probability. An additional, separate problem is the determination of the actual values of variable loads due to sea waves, which are irregular in time.

Due to the above and due to the fact that Lotos Petrobaltic has significant operational experience related to the use of CT pipes of identical construction and similar diameter (4.5") under similar conditions, it was decided that the safety assessment of the proposed new 4" pipe will take place on the basis of comparison of working conditions and stresses in the current 4.5 " and new 4" pipes. In the case of analysis of objects subjected to continuous cyclic stresses of variable amplitude, this method is definitely more reliable in relation to the determination of absolute stress values and estimation of fatigue life in years or months.

The following dimensions of the analyzed section of the injection pipe were assumed for analysis: $\mathrm{A}=16 \mathrm{~m}, \mathrm{~B}=82 \mathrm{~m}$, $\mathrm{R}=20 \mathrm{~m}$ and $\mathrm{E}=70 \mathrm{~m}$ (Fig. 1). On the basis of a separate study [4], the parameters of the wave loading the CT pipe suspended on the platform were set. Table 1 presents the values adopted for the needs of analyzes (the meaning of symbols in Fig. 1). These parameters correspond to the significant wave height at the return period of 100 years.

Tab. 1. Wave parameters introduced to the calculation

\begin{tabular}{|lc|c|c|}
\hline Wave height & $\mathrm{H}$ & {$[\mathrm{m}]$} & 9.9 \\
\hline Wavelength & $\mathrm{L}$ & {$[\mathrm{m}]$} & 152.6 \\
\hline Wave period & $\mathrm{T}$ & {$[\mathrm{s}]$} & 9.7 \\
\hline
\end{tabular}

To describe the wave motion using data for the wave according to Table 1 (due to the values of the L/B and H/B parameters) the theory of Stockes wave (approximating the fifth order) [5], [6] was used. It was used to determine the instantaneous values of velocity and acceleration of horizontal water particles (in the vertical coordinate $\mathrm{z}$ function), on which the load of system components depends according to the dependence (1) ([7]):

$$
\begin{aligned}
q= & C_{a} \rho_{w} \frac{\pi d^{2}}{4}\left(-a_{s}\right)+C_{M} \rho_{w} \frac{\pi d^{2}}{4} a_{w}+ \\
& +C_{D} \rho_{w} \frac{d}{2}\left|u_{w}-u_{s}\right|\left(u_{w}-u_{s}\right)
\end{aligned}
$$

where:

$\mathrm{q}$ - unit load $[\mathrm{N} / \mathrm{m}]$,

$\rho_{\mathrm{w}}-$ density of seawater $\left[\mathrm{kg} / \mathrm{m}^{3}\right]$,

$\mathrm{d}$ - outer diameter of the pipe [m],

$\mathrm{u}_{\mathrm{w}}-$ horizontal velocity of water particles (dependent on $\mathrm{z}$ ) $[\mathrm{m} / \mathrm{s}]$,

$\mathrm{u}_{\mathrm{s}}$ - horizontal pipe speed (depending on) $[\mathrm{m} / \mathrm{s}]$,

$\mathrm{a}_{\mathrm{w}}-$ horizontal acceleration of water particles (depending on) $\left[\mathrm{m} / \mathrm{s}^{2}\right]$,

$\mathrm{a}_{\mathrm{s}}$ - horizontal tube acceleration (dependent on) $[\mathrm{m} / \mathrm{s}]$,

$\mathrm{C}_{\mathrm{a}}$ - weight factor added [-],

$\mathrm{C}_{\mathrm{M}}$-coefficient of inertia [-],

$\mathrm{C}_{\mathrm{D}}$-coefficient of normal drag [-].

The values of $\mathrm{C}_{\mathrm{M}}$ and $\mathrm{CD}$ parameters depend on the local value of the Reynolds number in accordance with the guidelines contained in [8]. For analyzes it was assumed that the seawater density is $\rho_{\mathrm{w}}=1025 \mathrm{~kg} / \mathrm{m}^{3}$ and its dynamic viscosity $\mu=1.6 \times 10^{-3}$ [Belt] (to determine the Reynolds number). The calculations also take into account the additional inertia of the system (the so-called added mass) with the $\mathrm{C}_{\mathrm{a}}=1$ ratio [9].

\section{ANALYSIS OBJECT - CT PIPES}

During operation, injection water pipes are exposed to various loads. The most important of them are: bending moments and cutting forces (caused by sea waves); forces stretching the pipe wall (axial caused by weight and circumferential from the internal pressure of the injection water) as well as torsional moments caused by the action of offset force relative to the point of engagement of the pipe (depending on the direction of the wave inflow). The most common causes of pipeline failures are [10]: mechanical damage (due to impacts or external factors), internal or external corrosion, structural and material errors, and natural operational factors. CT pipes do not usually require joining, they are delivered in sections of appropriate length and wound, for transport purposes, on a roll of large diameter [11]. The technology of rolled pipelines has found wide application in the mining industry, for this reason they are also the subject of detailed research works, e.g. [12], [13]. Table 2 presents the most important geometrical and strength parameters of 
CT pipes analyzed in this work. The pipe used so far with a diameter of 4.5 " was made of X65C material. The material of the new 4" pipe (X70C) was characterized by increased durability resulting from the need to operate at an increased pressure level of water. As can be seen from the comparison of parameters, in addition to the increased strength of the material, the new pipe was also characterized by a greater wall thickness (at a smaller diameter).

Tab. 2. Comparison of selected geometric and material parameters of the analyzed CT pipes with sizes 4.5 " and 4 "

\begin{tabular}{|c|c|c|c|c|}
\hline parameter & unit & $4,5^{\prime \prime}$ pipe & 4" pipe & difference \\
\hline material & & $\mathrm{X} 65 \mathrm{C}$ & $\mathrm{X} 70 \mathrm{C}$ & - \\
\hline yield point $R_{e}$ & [MPa] & 448 & 483 & フ $8 \%$ \\
\hline strength limit $R_{m}$ & [MPa] & 530 & 552 & 入 $4 \%$ \\
\hline outer diameter of the pipe & {$[\mathrm{mm}]$} & 114.3 & 101.6 & $\searrow 12 \%$ \\
\hline wall thickness of the pipe & {$[\mathrm{mm}]$} & 6.35 & 7.62 & ス $20 \%$ \\
\hline section strength index for bending & {$\left[\mathrm{mm}^{3}\right]$} & 55051 & 49191 & $\searrow 12 \%$ \\
\hline cross-section of the pipe & {$\left[\mathrm{mm}^{2}\right]$} & 2152 & 2249 & ス $4 \%$ \\
\hline pipe material density (steel) & {$\left[\mathrm{kg} / \mathrm{m}^{3}\right]$} & \multicolumn{2}{|c|}{7810} & - \\
\hline $\begin{array}{r}\text { stiffness module of the pipe material } \\
\text { (steel) }\end{array}$ & {$[\mathrm{Pa}]$} & \multicolumn{2}{|c|}{$2.1 \times 1011$} & - \\
\hline insulation thickness & {$[\mathrm{mm}]$} & \multicolumn{2}{|c|}{1.83} & - \\
\hline density of insulation material (material) & {$\left[\mathrm{kg} / \mathrm{m}^{3}\right]$} & \multicolumn{2}{|c|}{1200} & - \\
\hline working water pressure & {$[\mathrm{MPa}]$} & 20 & 30 & $\lambda 50 \%$ \\
\hline $\begin{array}{r}\text { maximum pressure of the water being } \\
\text { pumped }\end{array}$ & {$[\mathrm{MPa}]$} & 25 & 33 & ス $32 \%$ \\
\hline
\end{tabular}

Preliminary results of the analysis show that the largest share in the value of stresses reduced in the pipe wall is bending and internal pressure of water. The value of circumferential stresses in the pipe wall (so-called hoop stress) induced by the action of internal pressure can be estimated using a simple relationship for thin-walled pressure vessels [14]. These stresses are respectively about $212 \mathrm{MPa}$ for a 4.5 " pipe at a pressure of $25 \mathrm{MPa}$ and about $204 \mathrm{MPa}$ for a 4 " pipe at a pressure of $33 \mathrm{MPa}$.

\section{CALCULATION MODEL}

CT pipe calculations were made using the Finite Element Method (FEM) [15]. FEM is widely used in the analysis of oil and gas extraction pipelines, e.g. to determine the impact of the seabed geometry on its loads [16] or the analysis of the pipeline installation process [17]. In this work, the analysis of the system on which the load variables associated with sea waves are working, the dynamic analysis of FEM (transient analysis) with activated large displacement effect has been used. The developed model together with the boundary conditions is shown in Fig. 2.

The model was composed of a CT tube, which was mapped using two-dimensional beam finite elements and a non-deformable seabed. It was assumed that the modeled pipe consists of a horizontal section (lying on the bottom of the sea), archways from a horizontal to vertical section and a vertical section protruding above the sea level (see Fig. 1). A regular division into finite elements with an average finite element length of approx. $0.2 \mathrm{~m}$ was applied. Geometric parameters of the pipe cross-sections and material data were adopted in accordance with the data contained in Table 2.

To take into account the impact of the analyzed pipeline with the seabed, contact elements were used. Contact pairs are defined between the horizontal and curved pipeline section and the surface located at the sea bottom $(z=-82 \mathrm{~m})$. The function of the contact elements was to mediate the transfer of loads between the pipe and the bottom as well as to limit the possibility of the analyzed elements moving below the wave direction 0 (towards $\mathrm{x}$ coordinate)

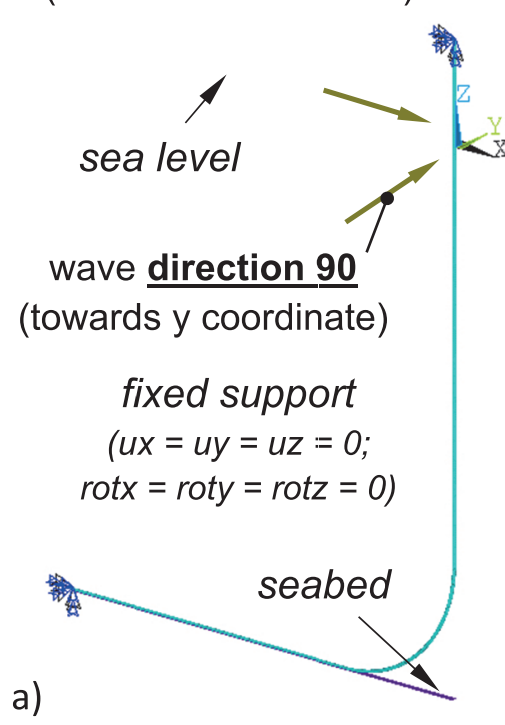

\section{fixed support}

$$
\begin{gathered}
(u x=u y=u z=0 ; \\
r o t x=\text { roty }=\text { rotz }=0)
\end{gathered}
$$

CT pipe

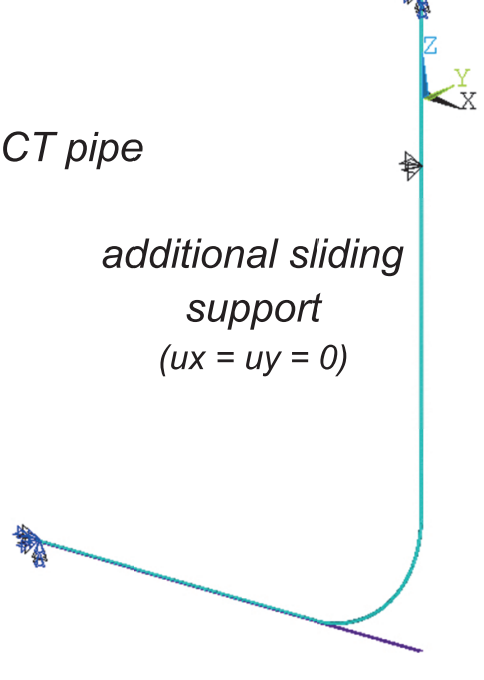

c)

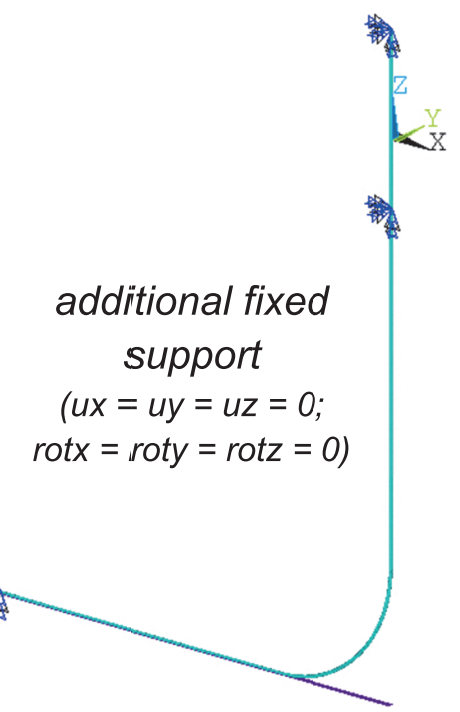

b)

) fixed fixation $(z=-10 \mathrm{~m})$ 
level of the bottom as a result of the load. It was assumed that the coefficient of friction for contact elements is 0.2 .

The model was confirmed by taking all degrees of freedom (translational and rotational) to the nodes located at the ends of the pipeline fragment included in the calculations. This boundary condition is a simplification of the reality of the real object operation, because, for example, during extreme sea waves the tube holder moves with the platform to which it is attached. Simplification, however, goes towards increasing the loads carried by the analyzed object (it increases the security of analyzes). The load of the model was (depending on $z$ coordinate) hydrodynamic unit pressure of water calculated in accordance with relationship (1). The calculations were made for two wave directions (see Fig. 2a): direction 0 (consistent with the direction of the $\mathrm{X}$ axis) and direction 90 - perpendicular to the previous one (consistent with the direction of the $\mathrm{Y}$ axis). In the next stage of work, for the variant of loading the pipe with the action wave from the 0 direction, the influence of additional restraint of the 4" pipe (located on the coordinate $\mathrm{z}=-10[\mathrm{~m}]$ ) in two configurations was also analyzed: sliding restraint (Fig. 2 b) and fixed (Fig. $2 \mathrm{c}$ ).

The solution of the task with periodically acting variable force in time, which is the load on the wave, requires defining not only the boundary conditions, but also the initial conditions. The initial state of movement of the CT pipe due to the waving affects the values of the relative velocities and accelerations of water loading the pipe (the hydrodynamic load depends on the instantaneous water velocities and the pipe). Knowledge of the exact initial conditions would allow limiting the required analysis time to a single period of action of the $\mathrm{T}$ wave. In the lack of knowledge about the initial state of the system (as in the case analyzed) it was assumed that it was at rest and the total analysis time was extended to $3 \mathrm{~T}$. During the calculations from 0 to $2 \mathrm{~T}$ the model of the system was put into motion and was intended only to obtain the initial conditions. In this way, repeatability of structure movements (as well as hydrodynamic loads) was obtained despite the lack of knowledge about initial conditions. All results presented in the study were obtained from calculations for the time from $2 \mathrm{~T}$ to $3 \mathrm{~T}$. The time step of the analysis was set to $0.004 \mathrm{~s}$. The analysis results, due to the size limitations of the database, were recorded every $0.02 \mathrm{~s}$, which for the time $\mathrm{T}=9.7$ s gives 485 sets of simulation results.

\section{SELECTED ANALYSIS RESULTS}

Fig. 3 shows the calculated time variation of the level of the wave profile with the parameters according to Table 1. For the presentation of the results 4 characteristic time moments were selected (points in Fig. 3): $t_{1}=0.1 \mathrm{~s}$ (sea level movement $\uparrow$ ), $\mathrm{t}_{2}=2.5 \mathrm{~s}$ (wave ridge), $\mathrm{t}_{3}=4.76 \mathrm{~s}$ (sea level movement $\downarrow)$ and $t_{4}=7.2 \mathrm{~s}$ (wave valley) for which selected analysis results were presented.

Fig. 4 compares the exemplary results of FEM calculation of the determined hydrodynamic unit load distributions of
4.5" and 4" pipes. The obtained load course was characterized by irregularity, and was different from the expected typical "smooth" distribution [2]. This can be explained by the appearance in the local model of flexible pipeline vibrations (of small amplitude) that were revealed in the results of FEM analysis. These vibrations change the continuous velocity distribution and relative acceleration of the fluid elements that wash the pipe, on which the hydrodynamic load components (related to flow resistance and inertia) depend.

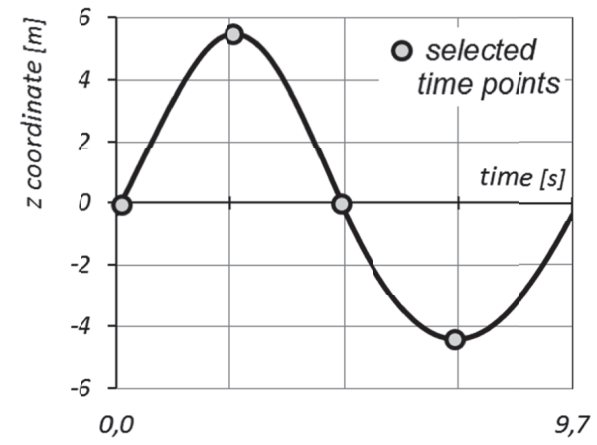

Fig. 3. Elevation wave profile; points are marked with time points selected for presentation of results

In the model used, the vibrations are triggered by cyclic collisions of fragments of the horizontal part of the pipeline with a model bottom. The collisions, due to the use of contact elements, are elastic in nature. This simplification is far from reality in relation to the seabed, which exhibits plasticity (sandy-clay soil [16]), and in the place where the pipe meets the seabed, as a result of their interaction, bottom depression may occur [18]. In addition, the model does not take into account the pre-stress of the system caused by stresses in the pipe walls after it has been laid and bent at the bottom. In fact, as the post-assembly observations indicate, the pipeline adopts due to its stiffness quite a gentle arch at the transition from the vertical to the horizontal section (chain line). As a result, the phenomenon of vibration in the real object observed in the analysis results probably does not occur at all or at least has less intensity.

a)

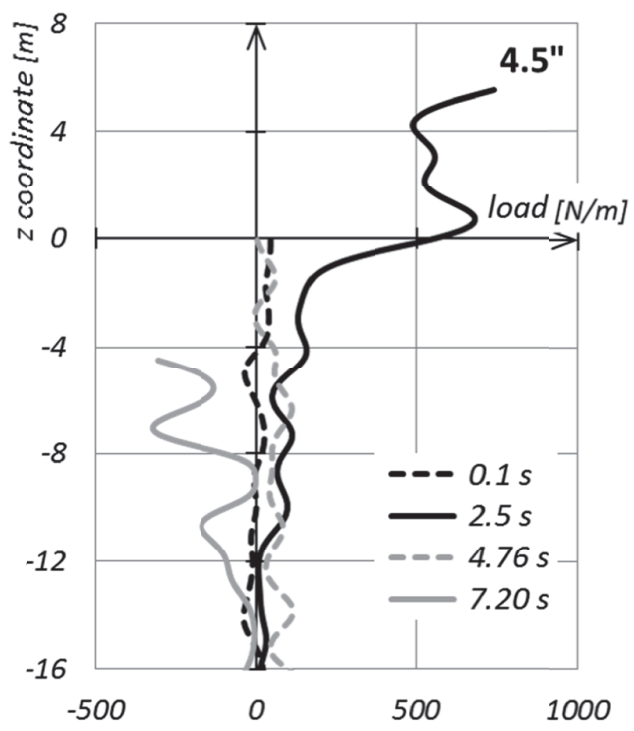

POLISH MARITIME RESEARCH, No 3/2018 
b)

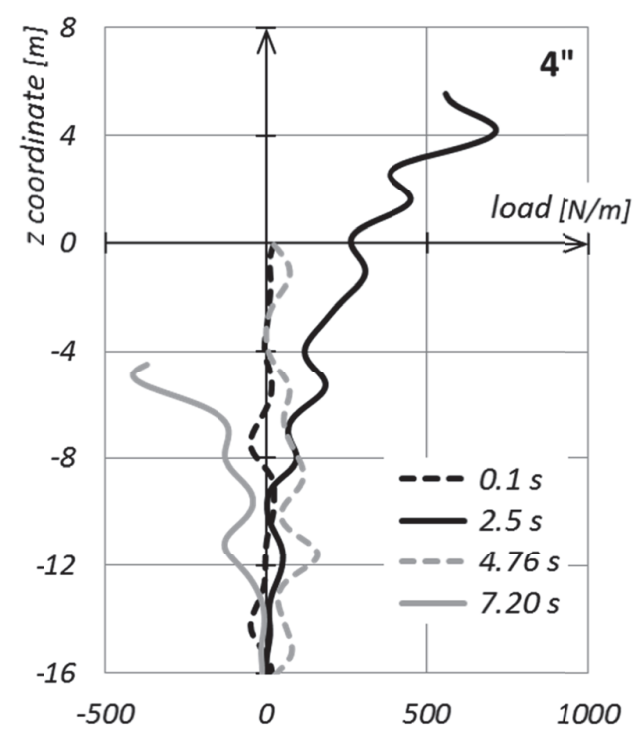

Fig. 4. Calculated MES distribution of unit load wave $[\mathrm{N} / \mathrm{m}]$ for selected time moments (wave direction 0, model without additional restraints): a) 4.5" pipe; b) 4" pipe

\section{DIRECTION 0}

This point compares the results of the FEM analysis obtained for both sizes of the analyzed pipes and the direction of the inflow of the wave (direction consistent with the pipeline line on the bottom, see Fig. 2 a).

Fig. 5 compares the results of displacements in the $\mathrm{x}$ direction of two selected pipeline points with coordinate $\mathrm{z}=0 \mathrm{~m}$ (calm level) and $\mathrm{z}=-41 \mathrm{~m}$ (half of the sea depth) as a function of analysis time. It can be noticed that the obtained displacement results as a function of analysis time for both pipes are almost the same. Only a slightly larger displacement, maximum by approx. $0.1 \mathrm{~m}$ (for point $\mathrm{z}=-41$ $\mathrm{m})$ was calculated for the 4.5 " pipe.

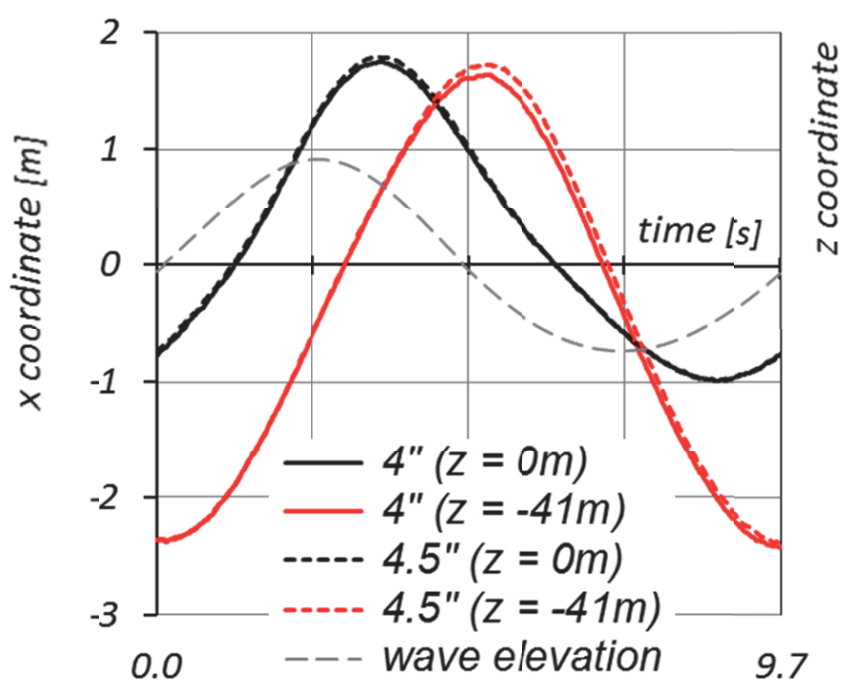

Fig. 5. Comparison of the results of FEM calculation of displacements in the direction of $x$ for the selected points of the 4" and 4.5" pipe model for the load with the direction 0
Fig. 6 shows a comparison of bending and tensile stress results in a 4 "(a) and 4.5 " pipe (b) at the anchoring point at the platform $(\mathrm{z}=16 \mathrm{~m})$.

a)

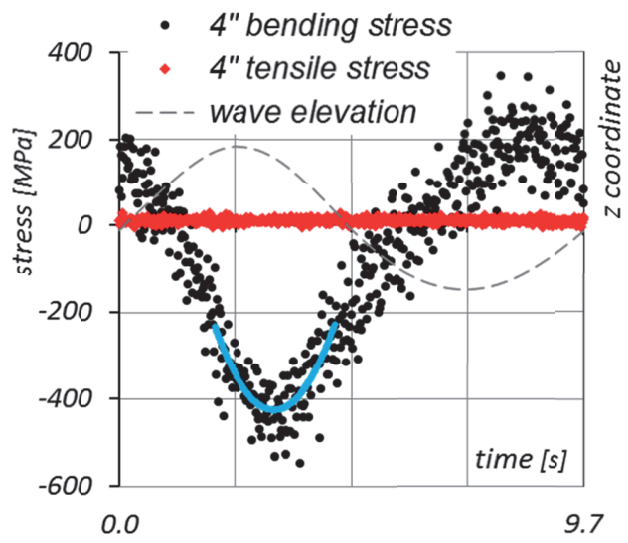

b)

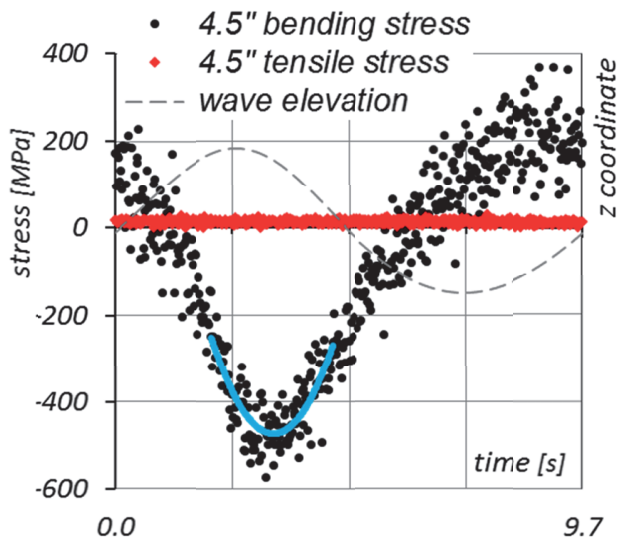

Fig. 6. Comparison of FEM calculation results of bending and tensile stresses [MPa] in restraint $(z=16 \mathrm{~m})$ as a function of analysis time: a) 4" pipe; $b$ ) 4.5" pipe

The obtained stress waveforms are not continuous and they are characterized by a step change in values in successive time moments. This is due to the aggregation of the effects of global bending of the pipe due to waving and local bending caused by vibrations of the pipeline. Both effects have different frequency. The change of stresses caused by local vibrations (generated by the elastic collision of the model bottom with the pipe) is probably only a feature of the model and this phenomenon does not occur in the real object. For this reason, to establish the maximum value of bending stresses, resulting only from waving, an exponential trend line for the stresses result determined from the time range near the expected maximum value (polynomial of the second degree, blue line in Fig. 6) was used. A similar methodology for determining bending stresses in the pipeline was used for the other analyzed cases. The maximum stresses calculated in this way occurred for time $t \approx 3.3 \mathrm{~s}$ and it was equal to approx. $426 \mathrm{MPa}$ for 4 " pipe and approx. $435 \mathrm{MPa}$ for 4.5 " pipe. The values of tensile stresses were comparable in both cases (on average about $11 \mathrm{MPa}$ for 4" and about 12.6 MPa for 4.5”). 


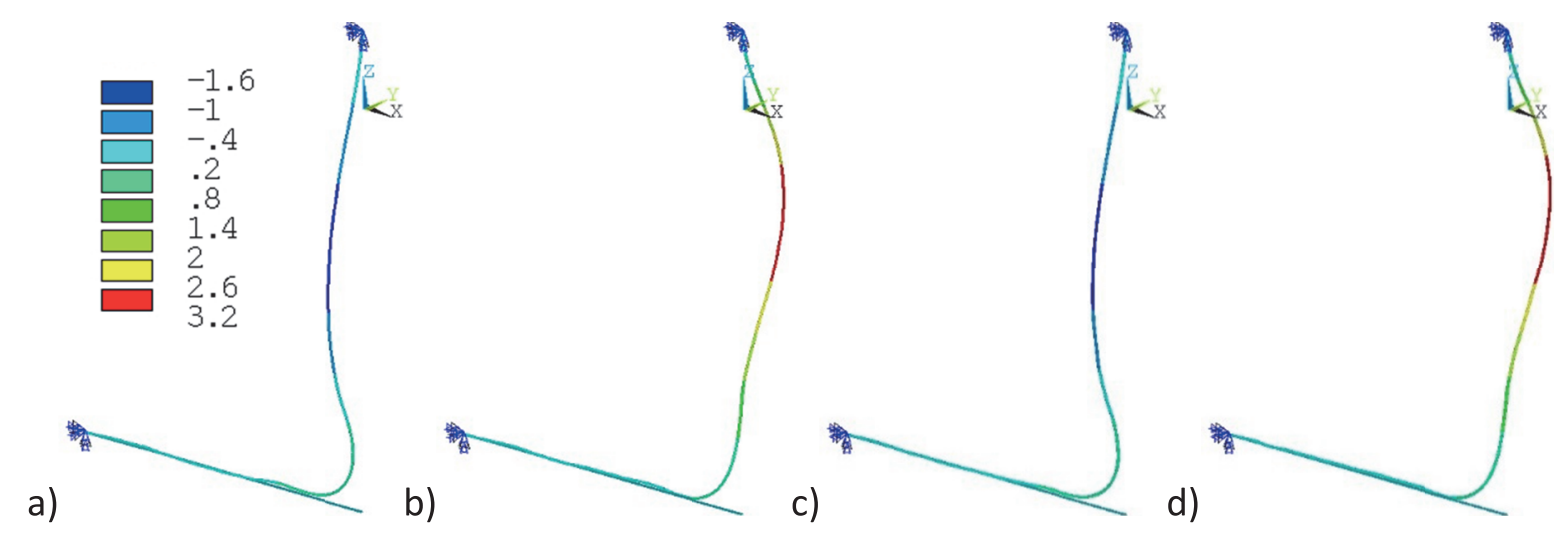

Fig. 7. Comparison of FEM results of pipe deformation in the y-axis direction $[\mathrm{m}]$ (increased $x 5$ ): a) 4 " $t 1=0.1 \mathrm{~s} ; b$ ) 4 " $t 3=4.76 \mathrm{~s} ; \mathrm{c}$ ) $4.5^{\prime \prime} t 1=0.1 \mathrm{~s}$; d) $4.5^{\prime \prime} t 3=4.76 \mathrm{~s}$

\section{DIRECTION 90}

This part of the work compares the results of FEM analysis obtained for both sizes of analyzed pipes and the direction of 90 wave inflow (direction perpendicular to the pipeline line on the bottom, see Fig. 2 a).

The obtained result of displacements in the y direction from the calculations of both pipes for two selected time moments $\left(t_{1}\right.$ and $t_{3}$ ) was compared in Fig. 7. The obtained deflections of both pipes have the same shape and similar values.

In Fig. 8a results of displacements in the y direction of two selected pipeline points with $\mathrm{z}=0 \mathrm{~m}$ (calmness level) and $\mathrm{z}=-41 \mathrm{~m}$ (half of the sea depth) as a function of analysis time were compared. The obtained results of calculations indicate that the displacements $y$ of the selected points of both pipes are almost identical. In Fig. $8 \mathrm{~b}$ the movement path of the pipeline point is compared with the coordinate $\mathrm{z}=-41 \mathrm{~m}$ in the $x-y$ plane due to waving. Only slight differences in the results of the calculated displacement values can be observed (especially in the $\mathrm{x}$ direction).

a)

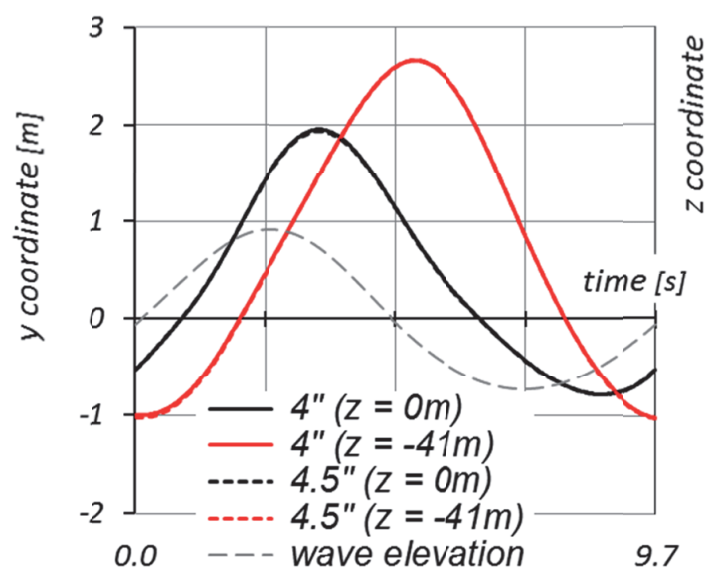

b)

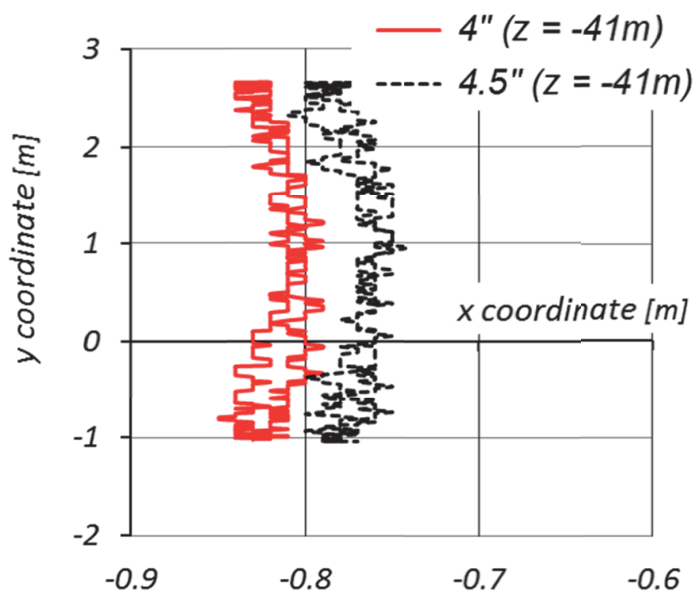

Fig. 8. Comparison of FEM calculation results for displacements of selected 4" and 4.5 "pipe points for load with a 90 direction: $a$ ) in the $y$ direction; $b$ ) point $z=-41 m$ in the $x-y$ plane

Fig. 9 shows a comparison of bending and tensile stress results in a 4 " (a) and 4.5 " pipe (b) at the anchoring point at the platform $(\mathrm{z}=16 \mathrm{~m})$. The maximum bending stress values calculated using the trend line were observed for time $\mathrm{t} \approx 3.2 \mathrm{~s}$. A slightly smaller value of extreme bending stresses (about $327 \mathrm{MPa}$ ) was calculated for a 4" pipe, for a 4.5 " pipe it was approx. $348 \mathrm{MPa}$. Similarly to the direction of load action, tensile stress values were significantly lower than bending stresses and comparable for both pipes (on average about 11 $\mathrm{MPa}$ for 4" and approx. 12.6 MPa for 4.5").

a)

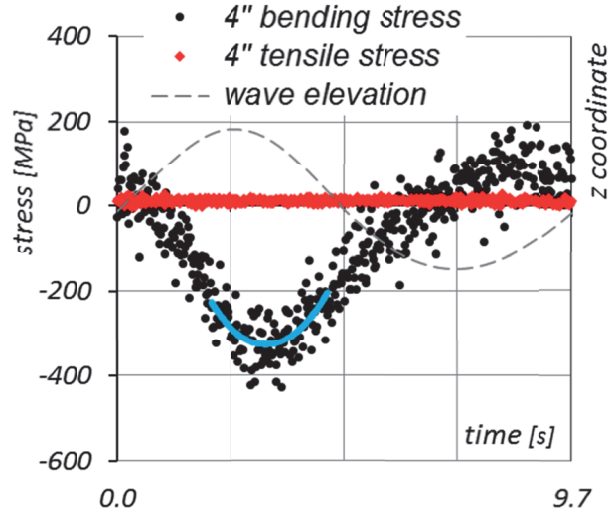


b)

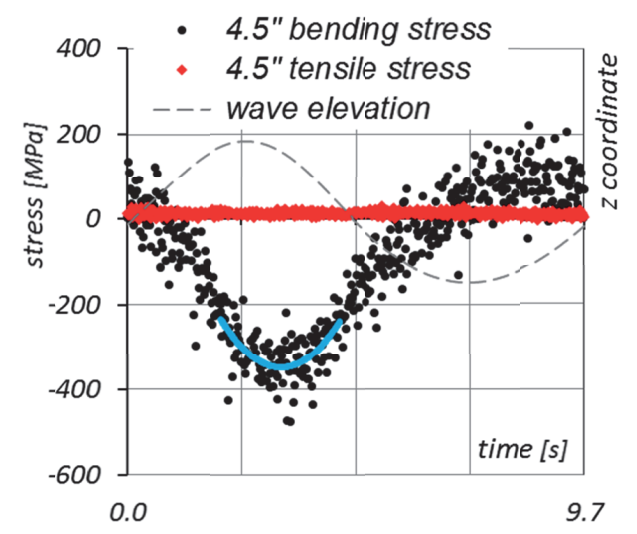

Fig. 9. Comparison of the results of FEM calculation of bending stresses and tensile stress [MPa] in restraint $(z=16 \mathrm{~m})$ as a function of analysis time: a) 4" pipe; b) 4.5 " pipe

\section{IMPACT OF ADDITIONAL PIPE FIXATION (DIRECTION 0)}

One of the ways to minimize the impact of bending the pipe caused by sea waves may be the use of an underwater holder that secures the pipe to the stationary leg of the platform. For this reason, it was computationally verified how the load and deformation of the pipe will change as a result of the additional immobilization at the coordinate $\mathrm{z}=-10 \mathrm{~m}$. The analysis was performed for the 4" pipe and load action from the 0 direction and two types of additional pipeline restraint: sliding (Fig. 2 b) and fixed (Fig. 2 c).

The comparison of the results of the pipeline displacement calculations in the direction of the $\mathrm{x}$ axis for the three restraint configurations and the two selected time moments ( $t 1$ and $t 3)$ is shown in Fig. 10. It can be noticed that the additional restraint reduces the calculated value of the system displacements due to the waving effect. This is particularly evident in the area of $<-10 \mathrm{~m}$, in which the largest displacement of the pipeline is observed without additional restraint. In this fragment, the pipeline with additional restraint achieves maximum displacements in the $\mathrm{x}$-direction from approx. $-1.8 \mathrm{~m}$ to 0.7 $\mathrm{m}$, while without additional restraint it is maximum approx. $\pm 2.5 \mathrm{~m}$.

In Fig. 11 the results of displacements in the $\mathrm{x}$ direction of two selected pipeline points were compared: $\mathrm{z}=0 \mathrm{~m}$ (calm level, Fig. A) and $z=-41 \mathrm{~m}$ (half of the sea depth, Fig. B) as a function of analysis time. The largest displacements were characterized by the result obtained for the pipe without

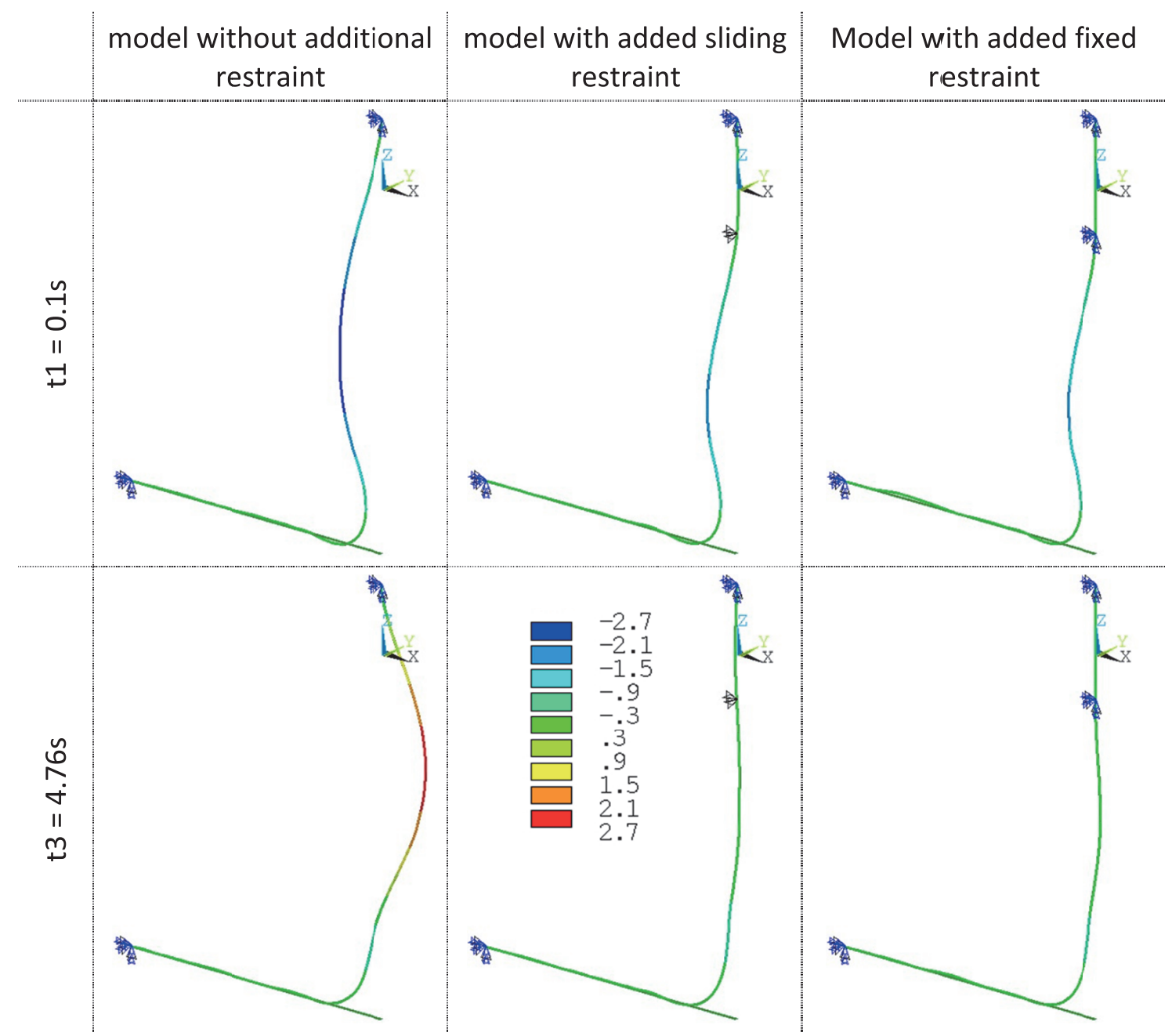

Fig. 10. Comparison of FEM results of 4" pipe deformation in the direction of the $x$ axis $[\mathrm{m}]$ (increased $x 5$ ) for different restraining variants and two time moments, load direction 0 
additional restraints, the smallest system with additional fixed restraint. The determined displacements of the point $\mathrm{z}$ $=0 \mathrm{~m}$ for models with additional restraint were of different character, while the result obtained for the pipeline coordinate with $=-41 \mathrm{~m}$ was very similar for both mentioned cases.

Fig. 12 shows a comparison of the variation in time of bending and tensile stress for models with additional restraint at the point $\mathrm{z}=16 \mathrm{~m}$ (fixing the tube at the platform) and in Fig. 13 for the point $z=-10 \mathrm{~m}$ (additional restraint).

a)

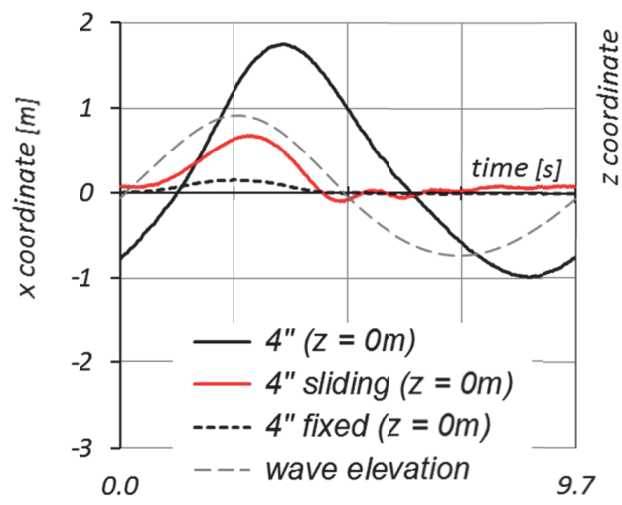

b)

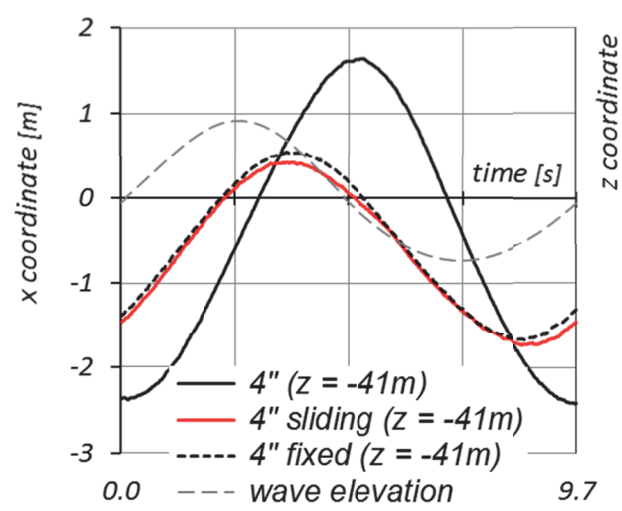

Fig. 11. Comparison of FEM displacement results for a 4 " pipe in the $x$ direction (load direction 0) for different restraint options: a) $z$ point $=0 \mathrm{~m} ; b$ ) point $z=-41 m$

a)

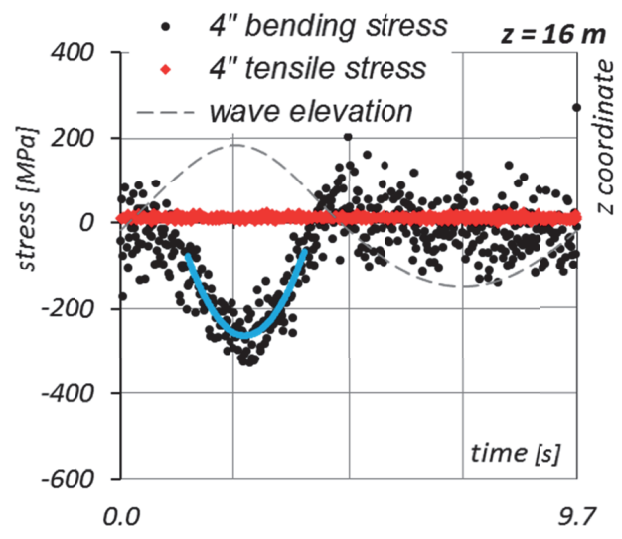

b)

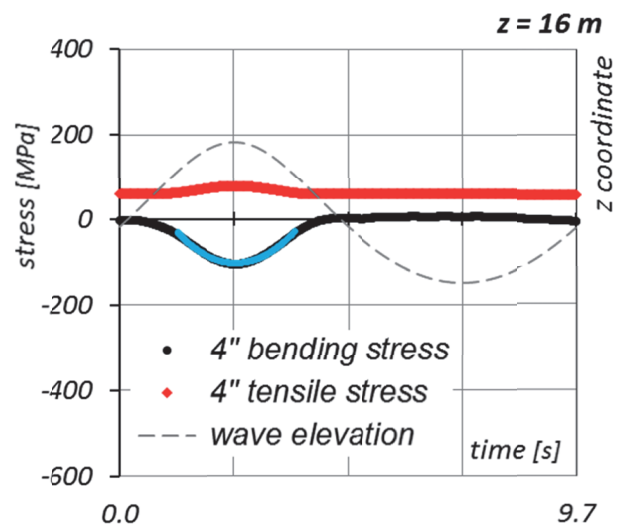

Fig. 12. The results of FEM calculation of bending and tensile stresses [MPa] in fixing the pipe to the platform with $=16 \mathrm{~m} ; a$ ) with sliding restraint; $b$ ) with fixed fixation

The calculated maximum value of bending stresses in fixing the pipe to the platform $(\mathrm{z}=16 \mathrm{~m})$ equals approx. $262 \mathrm{MPa}$ (for $\mathrm{t}=2.6 \mathrm{~s}$ ) for the case with additional sliding restraint and approx. $103 \mathrm{MPa}(\mathrm{t}=2.5 \mathrm{~s})$ for the case with an additional fixed restraint.

The obtained course of variation of bending stresses for a model with additional fixed restraint is continuous, because the full bonding of the model does not allow propagation of local vibrations above the level $\mathrm{z}=-10 \mathrm{~m}$. Another character has the course of tensile stresses that reach a comparable level to bending stresses (max. about $78 \mathrm{MPa}$ ). The peak of the tensile stress values for the moment of maximum bending stress is clearly visible $(\mathrm{t}=2.5 \mathrm{~s})$.

The time course of values of bending and tensile stress in the pipe at the level of additional restraint is shown in Fig. 13. The maximum stress value for the case of the floating restraint is about $260 \mathrm{MPa}(\mathrm{t}=2.8 \mathrm{~s})$ and for fixed restraint about $161 \mathrm{MPa}(\mathrm{t}=2.5 \mathrm{~s})$.

a)

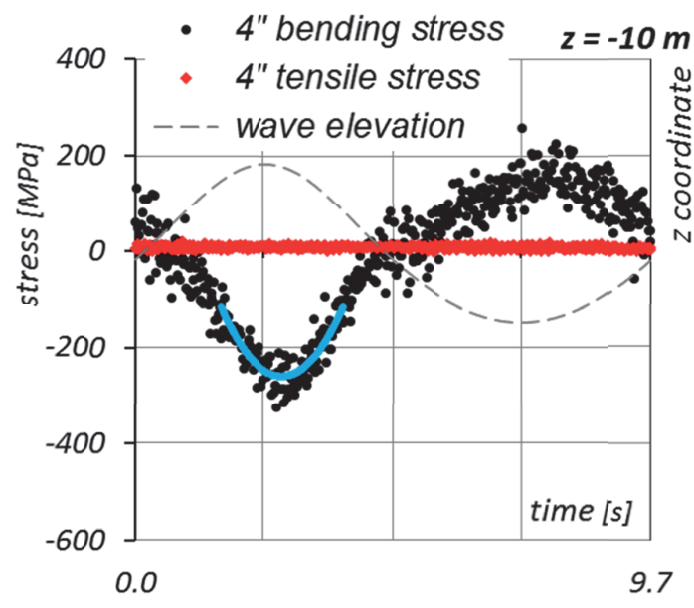


b)

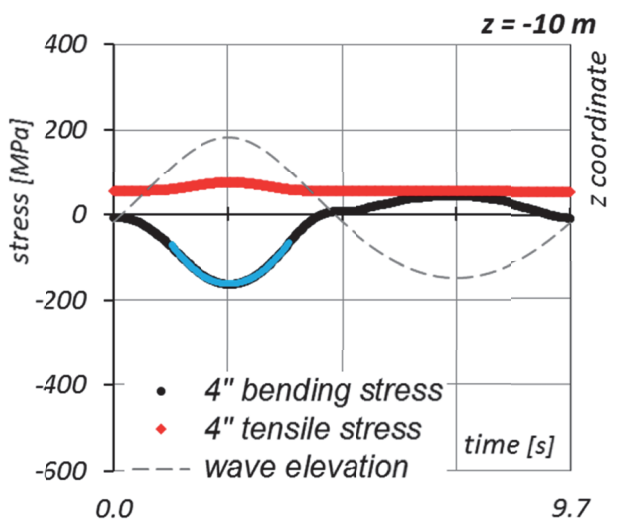

Fig. 13. Results of FEM calculation of bending and tensile stresses [MPa] in additional restraint with $=10 \mathrm{~m}$ of pipe; a) with sliding restraint; $b$ ) with fixed restraint

\section{DISCUSSION OF RESULTS}

In Table 3, the calculated values of loads and stresses in pipe restraints for all analyzed cases are summarized.

Tab. 3. Synthetic summary of the analysis results

\begin{tabular}{|c|c|c|c|c|c|c|c|}
\hline \multicolumn{2}{|c|}{} & \multicolumn{5}{c|}{ direction 0 } & \multicolumn{2}{c|}{ direction 90 } \\
\cline { 3 - 8 } \multicolumn{2}{c|}{} & $4.5^{\prime \prime}$ & $4^{\prime \prime}$ & $\begin{array}{c}4^{\prime \prime} \\
\text { sliding }\end{array}$ & $\begin{array}{c}4^{\prime \prime} \\
\text { fixed }\end{array}$ & $4.5^{\prime \prime}$ & $4^{\prime \prime}$ \\
\hline $\max \left|\sigma_{\mathrm{g}}\right|(\mathrm{z}=16 \mathrm{~m})$ & {$[\mathrm{MPa}]$} & $\mathbf{4 3 5}$ & $\mathbf{4 2 6}$ & 262 & 103 & 348 & 327 \\
\hline $\max \left|\sigma_{\mathrm{g}}\right|(\mathrm{z}=-10 \mathrm{~m})$ & {$[\mathrm{MPa}]$} & - & - & 260 & 161 & - & - \\
\hline $\max \left|\mathrm{M}_{\mathrm{g}}\right|(\mathrm{z}=16 \mathrm{~m})$ & {$[\mathrm{Nm}]$} & $\mathbf{2 3 9 5 0}$ & $\mathbf{2 0 9 5 0}$ & 12900 & 5060 & 19150 & 16100 \\
\hline $\max \left|\mathrm{M}_{\mathrm{g}}\right|(\mathrm{z}=-10 \mathrm{~m})$ & {$[\mathrm{Nm}]$} & - & - & 12800 & 7900 & - & - \\
\hline $\max \sigma_{\mathrm{r}}(\mathrm{z}=16 \mathrm{~m})$ & {$[\mathrm{MPa}]$} & 12.6 & 11.2 & 11.2 & $\mathbf{7 8 . 3}$ & 12.6 & 11.0 \\
\hline $\max \sigma_{\mathrm{r}}(\mathrm{z}=-10 \mathrm{~m})$ & {$[\mathrm{MPa}]$} & - & - & - & 75.1 & - & - \\
\hline $\max \mathrm{Fz}(\mathrm{z}=16 \mathrm{~m})$ & {$[\mathrm{N}]$} & 27200 & 25100 & 25200 & $\mathbf{1 7 6 0 0 0}$ & 27100 & 24700 \\
\hline $\max \mathrm{Fz}(\mathrm{z}=-10 \mathrm{~m})$ & {$[\mathrm{N}]$} & - & - & - & 169000 & - & - \\
\hline$\sigma_{\mathrm{obw}}\left(\mathrm{dla} \mathrm{p}_{\max }\right)$ & {$[\mathrm{MPa}]$} & 212 & 204 & 204 & 204 & 212 & 204 \\
\hline
\end{tabular}

The symbols in the table mean: $\sigma \mathrm{g}$ - bending stress, $\mathrm{Mg}$ bending moment, $\sigma \mathrm{r}$ - axial (tensile) stress, $\mathrm{Fz}$ - axial force and oobw - internal pressure stresses. Analyzing the results for a pipe without additional restraint, it can be concluded that stresses originating from bending and internal pressure are the dominant stresses. The level of bending stress is very similar in both pipes (4.5" and 4"), although small differences (in the order of $9-21 \mathrm{MPa}$ ) are noticeable in favor of the 4 " pipe. On the basis of the obtained results, it can also be stated that:

- the most unfavorable direction of the wave is the inflow of the wave along the $\mathrm{x}$-axis, i.e. along the fragment of the pipe laid on the bottom,

- calculations showed that the best solution limiting the bending stress caused by sea waves would be an additional fixing of the pipe in the holder mounted under the surface of the water, this solution effectively reduces the accept- able displacement of the pipe, thereby reducing bending stress,

- in the case of using an underwater holder for the sliding restraint, the horizontal reaction component is about 10 $\mathrm{kN}$, while for the holder with non-displacement restraint the horizontal component is about $5 \mathrm{kN}$, the vertical component about $176 \mathrm{kN}$ and the moment of force about 7900 $\mathrm{Nm}$,

- unfortunately, the use of additional fixation of the CT pipe is difficult to implement, because the mounting of the holder and the connection of the holder and pipeline would have to be made below the sea level in immersion by a team of divers. In addition, a separate issue to consider in this variant would be the durability of the underwater grip,

- no large displacement of the pipeline is currently observed. It seems that the decisive factor is its relatively small diameter and the recorded small wave pressure.

\section{CONCLUSION}

The calculations indicate that the working conditions chosen by Lotos Petrobaltic and 4" working on the B8 bed made of CT X70C material will be similar to the conditions in which the previously used CT 4.5 " pipes work on the Baltic Beta platform (B3 bed). On this basis, it can be concluded that the durability of the new 4" pipes will be similar to the durability of the existing CT 4.5 " pipes. In addition, it can be stated that:

- both currently used 4.5" pipes as well as new 4" pipes intended for installation on the modernized Petrobaltic platform work in difficult conditions and are heavily strenuous in extreme sea conditions. However, as the experience of exploitation indicates, the main problem of using CT pipes is their internal corrosion, which reduces the wall thickness and can lead to the breaking of the pipeline,

- all parameters of the new CT pipe to be installed on the modernized Petrobaltic platform were correctly selected: the material was changed to have a larger $\mathrm{R}_{\mathrm{e} a}$ nd $\mathrm{Rm}$, the wall thickness was increased and the diameter was reduced. As a result, it was possible to increase the injection pressure to about $30 \mathrm{MPa}$, maintaining the minimum permissible flow section. Of course, in order to increase reliability, it would be advisable to use a 4 " pipe with even thicker wall or greater strength. However, this could give rise to additional technical difficulties related to the applied pipeline laying technology (the impact of increased stiffness of the pipe on its rewinding and laying process). 
The obtained results of analyzes were used in further design work related to the installation of new CT 4 " pipes as part of the water injection system. Fig. 14 shows the CT tubes installed on the LOTOS Petrobaltic platform, which were the subject of the analyzes described.

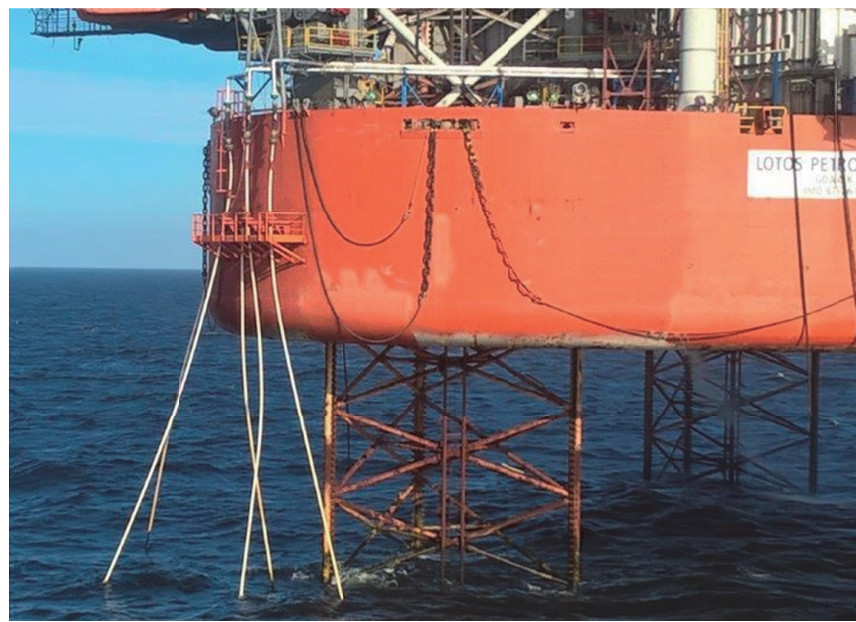

Fig. 14. CT 4" pipes operating in the water injection system on the LOTOS Petrobaltic platform

\section{ACKNOWLEDGMENT}

The authors would like to thank LOTOS Petrobaltic S.A. and A\&O EXPERT for cooperation and consent to publish the results of the work.

\section{LITERATURE}

1. Bai Q., Bai Y.: Subsea Pipeline Design, Analysis, and Installation (1 ${ }^{\text {st }}$ edition). Gulf Professional Publishing, 2014.

2. Guo B., Song S., Ghalambor A., Lin T.: Offshore Pipelines Design, Installation, and Maintenance (2nd edition). Gulf Professional Publishing, 2013.

3. Zhang Y.M., Fan M., Xiao Z.M., Zhang W.G.: Fatigue Analysis on Offshore Pipelines with Embedded Cracks. Ocean Engineering, 117 (2016), pp. 45-56

4. Kriezi E., Nerheim S., Gyllenram W.: Wind and Wave Statistics in the Southern Baltic Sea. SMHI 2008.

5. Skjelbreida L., Hendrickson J.A.: Fifth Order Gravity Wave Theory. Proceedings, 7th Conference of Coastal Engineering Ch. 10, p. 184-196, 1961.

6. Subrata C.: Handbook of Offshore Engineering. Volumes 1-2. Elsevier, 2005.

7. Faltinsen O.M. : Sea Loads on Ships and Offshore Structures. Cambridge University Press, 1993.
8. Massel S. (red).: Poradnik Hydrotechnika. Wydawnictwo Morskie Gdańsk, 1992.

9. Massey B. : Mechanics of Fluids. Taylor \& Francis, 2006.

10. Drumond G.P., Pasqualino I.P., Pinheiro B.C., Estefen S.F.: Pipelines, risers and umbilicals failures: A literature review. Ocean Engineering, 148 (2018), pp. 412-425.

11. Lyons W.C., Plisga G.J.: Standard Handbook of Petroleum and Natural Gas Engineering ( $2^{\text {nd }}$ edition). Gulf Professional Publishing, 2004.

12. Shaohu L., Hui X., Feng G., Qifeng J., Jiwei W., Ting Y.: Coiled Tubing Failure Analysis and Ultimate Bearing Capacity Under Multi-Group Load. Engineering Failure Analysis 79 (2017), pp. 803-811.

13. Falser S., Bridge C., Plamer A.C.: Interaction Between a Compliant Guide and a Coiled Tubing During Sub-Sea Well Intervention in Deep Water. Applied Ocean Research 32 (2010), pp. 454-459

14. Patnaik S., Hopkins D.: Strength of Materials. Elsevier, 2003.

15. ANSYS 14.5 Documentation. Swanson Analysis Inc, 2012.

16. Bai Y.: Pipelines and Risers. Elsevier Ocean Engineering Book Series, Elsevier Science, Vol. 3, 2001.

17. Chatzopoulou G., Karamanos S.A., Varelis G.E.: Finite Element Analysis of Cyclically-Loaded Steel Pipes During Deep Water Reeling Installation. Ocean Engineering, 124 (2016), pp. 113-124.

18. Katifeoglou S.A., Chatjigeorgiou I.K.: Dynamic interaction of catenary risers with the seafloor. Applied Ocean Research 38 (2012), pp. 1-15.

\section{CONTACT WITH THE AUTHOR}

\author{
Michał Wodtke \\ e-mail: mwodtke@pg.edu.pl \\ Gdańsk University of Technology \\ 11/12 Narutowicza St. \\ 80 - 233 Gdańsk \\ Poland
}

